\title{
Verbos de Movimento na Tradução Russo-Português
}

\author{
Noé Oliveira Queiroz Policarpo Polli
}

Resumo: Comparam-se os meios de descrição do movimento nos dois idiomas e apresentam-se situações, nas quais as necessidades da tradução produzem subsídios aos dicionaristas.

Palavras-chave: verbos de movimento, direção do deslocamento, posição do falante, tradução.

O principal auxiliar do tradutor são os dicionários. Eles apresentam-lhe a palavra desconhecida e encaixam-na na frase em construção. Abri-los ao acaso e reconhecer os vocábulos com a familiaridade de velho amigo é sempre agradável. Riqueza vocabular, porém, não basta para o domínio da língua de partida; é preciso conhecer, também, sob qual perspectiva os seus falantes veem o ser ou coisa, designado por esta ou aquela palavra.

Como ilustração do supradito escolheram-se o movimento e a sua descrição no português e no russo. No primeiro, toma-se sempre um ponto de referência fundamental, a localização do falante (местонахождение говорямего; doravante: LF): о sítio onde, no momento da fala, se encontra a pessoa que comunique, oralmente ou por escrito, o deslocamento dum animal ou objeto por terra. Em seguida, considera-se a orientação do movimento (направление двињения): se dirigido ao falante (движение к говорямему) ou se partido de onde ele está (движение от говорямего); usam-se os pares vir-trazer e ir-levar, respectivamente.

vir, trazer $\rightarrow \rightarrow \longrightarrow \rightarrow \mathrm{L} \bullet \mathrm{F} \rightarrow \longrightarrow \rightarrow \rightarrow$ ir, levar

Em russo, por sua vez, LF não tem nenhuma relevância. O que importa é se o deslocamento se produz em uma única direção ou em várias (ou, pelo me- 
nos, com retorno). O tradutor deverá estabelecer a orientação do deslocamento, tomando por base, por exemplo, um pronome: Идите С нами (со мной) [Vinde/ Venham conosco (comigo)]. Porém: Идите С ними [Ide/Vãa com eles/as - com qualquer pessoa que não seja o falante ou com grupo que não o inclua.].

Seria de esperar que os correspondentes verbos do aspecto perfeito (пойти е повХАТь) também pudessem indicar inda e vinda; no dicionário, porém, eles vêm destituídos de tal possibilidade:

ПОЕХАТЬ $\Delta$ сов 1. ir* $^{*}$; ; partir $v i$, viajar (omnравиmьсs $)^{1}$.

Contraponha-se a isso um trechinho do conto «Турист-единоличник» (Turista individual), de Ilf e Petrov. A personagem Vypolniaev não se rende às comodidades de uma excursão em grupo à Criméia, já que prefere viajar sozinha, e diz a colegas de fábrica que não os acompanhará:

— НЕ поеду! — сказал наконеи Выполняев. [Não irei! — disse, finalmente, Vypolniáev. $]^{2}$

Movimento partido do falante e, portanto, o conseqüente emprego de $\boldsymbol{i}$.

Os companheiros insistem com ele, usando, em lugar do Modo Imperativo, uma construção equivalente: dаваŭ (implícito) + verbo do aspecto perfeito na primeira pessoa do plural:

— Поедем С НАми, фабзаяи! (...) [Vem conosco, chefe.]

Фабзаяи упрямился. [O fabzaiats teimava no seu.]

— Поедем, — говорили ему — (...) $[\text { Vem / conosco/, — diziam-lhe }]^{3}$

O pronome oblíquo da primeira pessoa do plural, na primeira fala, e a pessoa da forma verbal, na segunda, indicam que o falante coparticiparia no movimento; isso torna o deslocamento de Vypolniáev dirigido a ele e leva ao uso de vir.

O papel decisivo, na escolha do verbo, coube à sintaxe da frase, na qual havia uma forma verbal ou pronome referente a uma das pessoas incluidoras do falante (nós). Outro exemplo provê-nos пойти, traduzido como:

1 VÓINOVA, N.; STÁRETS, S; VERKHUCHA, V.; ZDITOVIÉTSKII, F. Russko-portugálskii slovar (Dicionário russo-português). Moscou: Rússkii iazyk, 1989, p. 445.

2 ILF, I. e PETROV, E. Sobránie sotchiniénii v piati tomakh (Obras reunidas em cinco tomos). Moscou: Khudójestvennaia literatura, 1996, tomo 2, p. 333.

3 ILF, I. e PETROV, E. Obra citada, p. 332. 


\section{ПОЙТИ $\Delta$ сов 1. ir* vi; dirigir-se (para) (направиться) ${ }^{4}$.}

Todos conhecem a historinha da querela dum mancebo com o velho, a cuja guarda ele confiara dinheiro. O homem alega não haver recebido nada; o juiz pergunta, então, ao queixoso onde se teria passado o facto; o moço responde que sob uma determinada árvore, e recebe uma ordem insólita:

- Пойди и позови это дерево ко мне - сказал судъя. [Vai e chama cá essa árvore, - disse o juiz: $]^{5}$

O movimento partiria do sítio onde se encontrava o seu futuro realizador; portanto, пойти traduz-se como $\boldsymbol{i r}$.

Cerca de meia hora depois, volta o rapaz e diz:

- Аерево не пошло со мной, мудрый судвя!

No original, está dito que a árvore não se movera (não partira) do lugar - a ênfase está no ponto de partida (PP); já para nós outros, simplesmente não ocorrera um movimento, dirigido ao sítio onde o falante já se encontrava (o que está explicitado pelo adjunto adverbial со мной — comigo), isto é, ao pé do juiz — a ênfase está no ponto de chegada (PC); portanto:

- A árvore não veio [não quis vir] comigo, sábio juiæ!

Verbos com o prefixo при- fornecem outras situações, em que os dicionários nada podem fazer pelo tradutor. Vejamos:

ПРИНЕСТИ $\cos$ B 1. trazer* $v t$ (mж. перен.). ${ }^{7}$

Como descritor de movimento dirigido ao falante, está perfeito. Raskólnikov vai à casa da velha onzeneira e diz-lhe:

— Заклад принёс, вот-c! - Trouxe uma coisa pra empenhar, esta.

4 VÓINOVA, N.; STÁRETS, S; VERKHUCHA, V.; ZDITOVIÉTSKII, F. Obra citada, p. 447.

5 FINÁGUINA Iu. V. Rússkii iazyk kak inostránnyi (Possóbie po tchtiéniiu). Russo para estrangeiros (Suplemento para leitura). São Paterburgo: ITMO, 2014, p. 4.

6 FINÁGUINA, Yu. Idem.

7 VÓINOVA, N.; STÁRETS, S; VERKHUCHA, V.; ZDITOVIÉTSKII, F. Russko-portugálskii slovar (Dicionário russo-português). Moscou: Rússkii iazyk, 1989, p. 485.

8 DOSTOIÉVSKII, F. Prestupliéniie i nakazániie (Crime e castigo). Moscou: Rússkii iazyk, 1984, p. 19. 
Acontece, porém, que o verbo também pode traduzir-se como levar. No início do filme «Приезжая»/A forasteira (Mosfilm, 1977) ${ }^{9}$, uma moça conversa com um pescador, às margens dum lago; ele dá-lhe dois peixes, e ela diz, envergonhada de não estar com dinheiro:

\section{- Вы скажите, сколько надо и где живёте, я принесу.}

Os dois encontram-se no vilarejo V. Se ela morasse em outro povoado ( $\left.V^{\prime \prime}\right)$, o movimento seria de $\mathrm{V}^{\prime \prime}$ para $\mathrm{V}$, onde ela se encontra no momento da fala $\left(\mathrm{V}^{\prime \prime}\right.$ $\rightarrow \mathrm{V}=\mathrm{LF}=\mathrm{PC})$, e dirigido, portanto, ao falante:

- Diga quanto devo e onde mora, e eu lhe trarei/virei trazer-lhe [o dinheiro].

Ambos, porém, habitam em V; este constitui o espaço maior, em cujo interior ocorreria o deslocamento dela; o ponto inicial seria a sua casa, e o final, a morada dele, não o lago $(\mathrm{LF}=\mathrm{PP})$; isso configuraria um movimento partido da falante:

- Diga quanto devo e onde mora, e eu lhe levarei/irei levar-lhe [o dinheiro].

Se, entre vir e chegar, há muita afinidade semântica, em russo ela é total, pois os dois traduzem-se por um mesmo verbo com o prefixo при-, por exemplo:

ПРИЙТИ $\Delta$ сов 1. vir* vi, chegar vi; vir de volta, voltar vi (вернуться) $)^{10}$.

Isso é um complicador da tradução. Testemunha-o um caso bem simples: como verter «Грачи прилетели», nome do famoso quadro de Alekséi Savrássov?

As gralhas são as núncias da Primavera, e o seu retorno de países mais quentes aguarda-se com impaciência; assim, «As gralhas chegaram»—o realizador do movimento, dirigido aonde estava o falante, era esperado por este. Se, com o aquecimento global, aves tropicais sul-americanas se aventurarem por terras russas, as pessoas dirão: Колибри прилетели! Vieram beija-flores! — agora, o realizador do movimento, dirigido aonde se encontrava o falante, não era esperado por este.

Veja-se, agora, a conversa de Razumíkhin com Raskólnikov, à saída duma taberna. O primeiro diz ao segundo que, naquele dia, festejaria a sua mudança para nova morada, e convida-o a comparecer ali:

9 Disponível em: https://www.youtube.com/watch?v=1 gnHVC0ikX0

10 VÓINOVA, N.; STÁRETS, S; VERKHUCHA, V.; ZDITOVIÉTSKII, F. Russko-portugálskii slovar (Dicionário russo-português). Moscou: Rússkii iazyk, 1989, p. 483. 
— Ты знаешь, у меня сегодня собираются на новоселье, может быть уж и пришии теперь, Аа я там Аядю оставиц, (...) — принимать приходящих. (...) Зайлёшь, что ми?

- Sabe, hoje bá reunião lá na minha nova casa, pra comemorar a minha mudança, talvez até já tenham chegado, mas eu deixei o meu tio lá, (...) — prá receber os que fossem chegando. (...) Pois então, passarás por lá?

— Не прилу, Разумихин! — Раскольников повернулся и пошёл прочь.

- Não irei, Razumíkbin! — Raskólnikov virou-se e foi-se.

- Об заклаА, что приАёшь! - крикнул ему вдогонку Разумихин.

- Pois eu aposto que tu virás! - gritou-lhe atrás Razumíkbin. ${ }^{11}$

O mesmo verbo recebeu três traduções diferentes. O dicionário contempla duas delas; uma, como chegar, por indicar a culminação do movimento de alguém para um sítio (tenham chegado), e a outra, como vir, por indicar um deslocamento (presumido) de alguém (Raskólnikov) à nova morada do falante, Razumíkhin, que о esperaria por lá. Porém прийти, na segunda aparição, refere-se a um movimento que partirá do falante (agora, Raskólnikov), e deve, portanto, traduzir-se como ir.

Em conformidade com a norma da língua russa para a descrição do movimento, que é o critério da "unidirecionalidade ou multidirecionalidade", o Dicionário de Russo-Português apresenta os verbos com o prefixo no- ou $\boldsymbol{n p u}$ - como indicadores de deslocamento numa única direção: ou de ida/levada (para os primeiros) ou de vinda/trazida (para os segundos).

Os exemplos, no entanto, bastam a mostrar que, pelo critério lusófono da "localização do falante", o movimento representado ao menos por tais verbos compreende dois deslocamentos opostos sob a mesma designação, os quais, em português, recebem cada qual o seu próprio nome.

O tradutor deverá estabelecer PP e PC e, em seguida, LF em relação aos dois; na escolha do verbo certo, ajudá-lo-á o contexto ou algum elemento da oração. 